\title{
Analysis of how obtaining melanocytes by magnetic cell separation contributes to autoepidermal transplantation technology in treating leucoderma
}

\author{
Xingyu Mei ${ }^{A-E}$, Jie Huang ${ }^{B, E}$, Yue Sun ${ }^{B}$, Zhouwei $W^{B}{ }^{B}$, Weimin Shi ${ }^{\mathrm{F}}$ \\ Shanghai General Hospital, Shanghai Jiao Tong University School of Medicine, China \\ A - research concept and design; $\mathrm{B}$ - collection and/or assembly of data; $\mathrm{C}$ - data analysis and interpretation; \\ $D$ - writing the article; $E$ - critical revision of the article; $F$ - final approval of the article
}

Address for correspondence

Weimin Shi

E-mail:shi128_1@tom.com

Funding sources

This study was funded by the National Natural Science Foundation of China (grant No. 81703140).

Conflict of interest

None declared

Received on August 8, 2018

Reviewed on August 27, 2018

Accepted on November 18, 2019

\begin{abstract}
Background. Leucoderma, a depigmentation of the skin, is a common disease in humans, and has been observed in cattle, horses and buffalo as well.

Objectives. To analyze the correlation between melanin stem cells and the differentiation and proliferation of melanocytes (MCs).

Material and methods. Magnetic cell separation was used to separate melan-A+ cells and PAX3 + cells, which were cultured in vitro. The L-DOPA staining was used to observe cell morphology; Cell Counting Kit- 8 (CCK8) was used to determine the cell proliferation rate; and flow cytometry (FCM) was used to determine cell cycle changes. The relative mRNA levels of melanocyte-inducing transcription factor (MITF), dopachrome tautomerase (DCT) and melan-A in cells were determined with reverse-transcription polymerase chain reaction $(R T-P C R)$.
\end{abstract}

Results. The number of $\mathrm{MC}$ dendrites increased and extended continually during in vitro culture following magnetic cell separation. The proportion of positive L-DOPA staining cells increased from a baseline $40.70 \%$ to $82.03 \%$, and the cell proliferation rate increased from $335.0 \%$ at D3 to $1577.4 \%$ at D20. The results of FCM showed that the cell proportion at the G1 stage in the D20 group was significantly lower than the D3 group; the cell proportion at the G2/M stage also decreased significantly. The expression of MITF and melan-A increased as the culture time increased, while the expression of DCT decreased.

Conclusions. The number of MC stem cells decreased and mature MCs increased gradually, indicating that $M C$ stem cells can gradually differentiate into mature MCs during in vitro culture following magnetic cell separation.

Key words: MSCs, MCs, magnetic cell separation, leucoderma
Cite as

Mei X, Huang J, Sun Y, Wu Z, Shi W. Analysis of how obtaining melanocytes by magnetic cell separation contributes to autoepidermal transplantation technology in treating leukoderma. Adv Clin Exp Med. 2020;29(12):1479-1486. doi:10.17219/acem/114339

DOI

10.17219/acem/114339

Copyright

Copyright by Author(s)

This is an article distributed under the terms of the

Creative Commons Attribution 3.0 Unported (CC BY 3.0)

(https://creativecommons.org/licenses/by/3.0/) 


\section{Introduction}

Leucoderma, a depigmentation of the skin, is a common disease in humans, and has been observed in cattle, horses and buffalo as well. Its main characteristic is the appearance of limited or extensive discoloration of areas of the skin, with distinct boundaries. Most of the patients are teenagers. Leucoderma affects nearly $2 \%$ of the world population. ${ }^{1}$ The causes of leucoderma are complex and its pathogenesis can be divided into neurosexual theory, immunology theory, oxidation and reduction theory, transformation theory, among others. ${ }^{2}$ The mechanisms causing melanocyte $(\mathrm{MC})$ destruction or dysfunction are an important part of the pathogenesis of leucoderma. Leucoderma causing large areas of depigmentation that affect patients' appearance and quality of life is especially difficult to treat. The main treatments are external hormones, calcineurin inhibitors, photosensitizers, phototherapy, and surgical transplantation. ${ }^{3}$ Surgical transplantation includes epidermal transplantation and melanoma cell transplantation. Therefore, the cultivation of MCs is important in autoepidermal transplantation technology.

Melanocytes are phenotypically prominent but histologically inconspicuous skin cells. They are responsible for the pigmentation of skin and hair, and thereby contribute to the appearance of the skin. ${ }^{4}$ Mutations of the function or number of MCs can lead to a series of refractory pigmentation diseases, such as leucoderma and chloasma. The surface dependent antigens of MCs have melanoma antigen recognized by $\mathrm{T}$ cells-1 (melan-A), melanocyte-inducing transcription factor (MITF), tyrosinase (TYR), and tyrosinase-related protein-2 (TRP-1). ${ }^{5}$ MelanA is synthesized by the melanosomes and endoplasmic reticulum of MCs, and has been identified as a marker antigen for mature MCs. ${ }^{6}$ Research shows that the cultivation of MCs is difficult. As compared with the other main types of skin cells, the percentage of MCs in epidermis cells is low, as is mitotic activity, which leads to the rapid growth of other cells, such as keratinocytes (KCs) and fibroblasts (FBs). ${ }^{7}$ Reports have shown that MC stem cells (MSCs) can differentiate into mature MCs in leucoderma patients. ${ }^{8}$ Most MSCs stay in the resting stage and can turn into MCs when stimulated by the related cytokines, which induces the formation of melanin. Current research on the mechanisms of MCs and the proliferation and differentiation of MSCs is mainly based on mice, while research on human MCs and MSCs is rarer. ${ }^{9}$ At the same time, regarding the co-culture of MCs, few reports in the literature have discussed whether MSCs participate in the differentiation of MCs. Therefore, further study of MSCs on changes in pigment and the mechanisms and treatment of related diseases has major significance. Since foreskins contain a relatively high density of $\mathrm{MCs},{ }^{10}$ they are the main cell type for the cultivation of MCs.

In this study, the enzyme digestion method was used to isolate and obtain skin cells in normal human foreskin tissue. Magnetic cell sorting (MACS) was used to isolate PAX3+ MSCs and mature melan-A+ MCs from primary hybrid cells. The L-DOPA staining was used to determine the cell proliferation rate, cell cycle and related specific markers.

\section{Material and methods}

\section{Obtaining tissue to culture}

Normal skin tissues were obtained from men aged 2050 years who underwent circumcision in the Urinary Surgery Department of Shanghai First People's Hospital (China) between February 2017 and December 2017. All the participants signed informed consent forms. Patients with a chronic skin history, type 2 diabetes, cardiovascular disease (CVD), chronic gastritis, any history of leucoderma, hyperthyroidism, systemic lupus erythematosus, or other autoimmune-related diseases were excluded.

\section{Tissue cell culture}

The prepuce tissues were washed 3 times in $30 \mathrm{~mL}$ of phosphate-buffered saline (PBS). Then, they were cut into approx. $2 \times 2 \mathrm{~mm}$ squares with sterile scissors, put in $40 \mathrm{~mL}$ of $0.05 \%$ trypsin-EDTA ( $8 \mathrm{~mL}$ of $0.25 \%$ trypsinEDTA $+32 \mathrm{~mL}$ of PBS) and refrigerated overnight at $4^{\circ} \mathrm{C}$ to digest. Then, $40 \mathrm{~mL}$ of $0.05 \%$ collagenase was added to the digested tissues and stirred with a magnetic stirrer for $2 \mathrm{~h}$ to digest. Afterwards, the samples were filtered and centrifuged at $1800 \mathrm{rpm}$ for $5 \mathrm{~min}$. Cells were resuspended in $1 \%$ human melanocyte growth supplement-2 (HMGS-2) and $0.04 \mu \mathrm{g} / \mathrm{mL}$ of amikacin keratinocyte serum-free medium. Following this, $100 \mu \mathrm{L}$ of the re-suspending solution was taken out and $25 \mu \mathrm{L}$ of trypan blue was added to the mix for cell counting. Cell concentration was adjusted and inoculated to T75 culture flasks at a density of $1 \times 10^{6}$ per flask, and then the cells were put in an incubator with $5 \% \mathrm{CO}_{2}$ at $37^{\circ} \mathrm{C}$.

After $24 \mathrm{~h}$, the primary cell culture dish was taken out of the incubator and washed with $15 \mathrm{~mL}$ of PBS. The cells were put back in the incubator with $5 \% \mathrm{CO}_{2}$ at $37^{\circ} \mathrm{C}$ and the cell morphology was observed regularly under an inverted microscope. A subculture was performed when cell growth density reached $60 \sim 70 \%$.

\section{Magnetic beads}

Twenty microliters of magnetic beads marked with biotin, $20 \mu \mathrm{L}$ of PAX-3 antibody marked with biotin and $20 \mu \mathrm{L}$ of melan-A antibody marked with biotin were refrigerated overnight at $4^{\circ} \mathrm{C}$. The previously separated skin-cell mixes were taken out of the incubator and pancreatin was added until the cells became round under the microscope. The cell solution was transferred to a $15 \mathrm{~mL}$ centrifuge 
tube and centrifuged at $1000 \mathrm{rpm}$ for $10 \mathrm{~min}$. Five hundred microliters of PBS was used to suspend cells, and biotin magnetic bead with PAX-3 and melan-A antibody was added to the cells for $90 \mathrm{~min}$. Cells were obtained by centrifugation and put in the MS separation column (Miltenyi Biotec Technology \& Trading; Shanghai, China). Magnetic bead-marked cells were obtained and cryopreserved at $-80^{\circ} \mathrm{C}$.

\section{Hematoxylin staining}

A histological evaluation was performed after 3 weeks. The hydrogels were fixed overnight in $4 \%$ paraformaldehyde at $4^{\circ} \mathrm{C}$ and transferred to $70 \%$ ethanol until embedded in paraffin according to standard histological techniques. Sections were stained with hematoxylin and eosin (H\&E) for general cell morphology and using the von Kossa method to characterize the mineralization.

\section{L-DOPA staining}

Cells adhering to the wall were washed in PBS, and 4\% triformol was added for fixation at room temperature for $10 \mathrm{~min}$. After washing 3 times with PBS, $10 \mathrm{~mL}$ of $0.1 \mathrm{M}$ phosphate buffer (PB) was added and the cells soaked for $10 \mathrm{~min}$. The supernatant was discarded, 0.1\% L-DOPA was added and the cells were put in an electric heat blower drier to stain for $4 \mathrm{~h}$. Four fields were selected under a microscope, and the number of cells in each field was calculated.

\section{Cell proliferation}

Cell growth was analyzed using a WST-8 Cell Counting Kit-8 (CCK-8; Beyotime, Nanking, China). Cells $\left(7.5 \times 10^{3}\right)$ suspended in $100 \mu \mathrm{L}$ of RPMI 1640 medium containing $10 \%$ fetal bovine serum (FBS) were seeded in 96-well plates and incubated for 2 days. The CCK- 8 solution $(10 \mu \mathrm{L})$ was added to each well and the cultures were incubated at $37^{\circ} \mathrm{C}$ for $90 \mathrm{~min}$. Absorbance at $450 \mathrm{~nm}$ was measured using an immunoreader C10066-50 (Hamamatsu Photonics; Hamamatsu, Japan). The results were plotted as means \pm standard deviation (SD) of 3 separate tests, with 4 measurements per test for each of the experimental conditions.

\section{Cell cycle}

Cell cycle distribution was analyzed using flow cytometry (FCM). After the treatments outlined above, the cells were trypsinized, rinsed with PBS, fixed with $70 \%$ ethanol at $4^{\circ} \mathrm{C}$ overnight, and then treated with RNaseA $(0.02 \mathrm{mg} /$ $\mathrm{mL}$ ) in the dark at room temperature for $30 \mathrm{~min}$. The cells were resuspended in $0.05 \mathrm{mg} / \mathrm{mL}$ propidium iodide and analyzed with a flow cytometer (Becton, Dickinson, Franklin Lakes, USA). DNA histograms were analyzed using ModFit
LT v. 2.0 software (Verity Software House, Topsham, USA). For each sample, at least 104 events were recorded.

\section{Tyrosinase activity determination}

Cultured cells that had undergone magnetic cell separation were inoculated on 96-well plates with $1 \times 10^{5}$ cells/ well and incubated with $5 \% \mathrm{CO}_{2}$ at $37^{\circ} \mathrm{C}$ for cultivation. After $24 \mathrm{~h}$, the supernatant was discarded and the precipitate was washed twice with PBS. To each well, $500 \mu \mathrm{L}$ of culture medium was added; after magnetic bead separation, D3 cells were taken as the control. Next, $160 \mu \mathrm{L}$ of $10 \mathrm{~g} / \mathrm{L}$ Triton X-100 (pH 7.5) was added to each well, and the culture plate was put in $-80^{\circ} \mathrm{C}$ refrigerator for $30 \mathrm{~min}$. Then, the cells were split at $37^{\circ} \mathrm{C}$ for $4 \mathrm{~h}$ with $100 \mu \mathrm{L}$ of $0.1 \%$ L-DOPA solution added to each well. After $4 \mathrm{~h}$, the absorbance value in each well was determined. Tyrosinase relative activity was calculated as „(eq. 1):

$\begin{aligned} & \text { tyrosinase } \\ & \text { relative } \\ & \text { activity }\end{aligned}=\frac{\begin{array}{c}\text { (average absorbance of the experimental group - } \\ - \text { average absorbance of the blank group) }\end{array}}{\begin{array}{c}\text { (average absorbance of the control group - } \\ - \text { average absorbance of the blank group) }\end{array}}$

\section{RNA isolation and quantitative RT-PCR}

Based on the manufacturer's instructions, we extracted total mRNA from the retinal samples using TRIzol Reagent (Life Technologies, Grand Island, USA). A pipette was used mix the samples and then transfer them to $1.5 \mathrm{~mL}$ Eppendorf (EP) tubes, and the samples were kept standing for $5 \mathrm{~min}$ to separate the nucleic acid protein complex. To each EP tube, $1 \mathrm{~mL}$ of Trizol and $200 \mu \mathrm{L}$ of pre-cooled chloroform was added. The tubes were shaken for $15 \mathrm{~s}$ and centrifuged at $4^{\circ} \mathrm{C}, 12,000 \mathrm{rpm}$, for $15 \mathrm{~min}$. We drew the aqueous phase into fresh $1.5 \mathrm{~mL}$ EP tubes and added $0.5 \mathrm{~mL}$ of isopropanol. The mixture was centrifuged at $4^{\circ} \mathrm{C}, 12,000 \mathrm{rpm}$, for $15 \mathrm{~min}$. After removing the supernatant, $1 \mathrm{~mL}$ of pre-cooled $75 \%$ ethanol was added to wash the RNA precipitate; this procedure was repeated 3 times. Then, the RNA precipitate was dried in a vacuum and its concentration was determined with a NanoDrop 1000 spectrophotometer (NanoDrop Technologies, Wilmington, USA). One microliter of Ologo dT $(0.5 \mu \mathrm{g} / \mu \mathrm{L}), 2 \mu \mathrm{g}$ of total RNA and $12 \mu \mathrm{L}$ of diethypyrocarbonate (DEPC) were added to polymerase chain reaction (PCR) tubes. After being mixed evenly, the tubes were placed in a $65^{\circ} \mathrm{C}$ water bath for $5 \mathrm{~min}$, and then immediately placed on ice. Reverse transcription was performed at $55^{\circ} \mathrm{C}$ for $30 \mathrm{~min}$, with initial activation for $15 \mathrm{~min}$ at $95^{\circ} \mathrm{C}$; next, 40 cycles of denaturation were conducted at $94^{\circ} \mathrm{C}$ for $15 \mathrm{~s}$, then annealing for $30 \mathrm{~s}$ at $55^{\circ} \mathrm{C}$ and extension for $30 \mathrm{~s}$ at $72^{\circ} \mathrm{C}$ were performed. The expression level was normalized using U6 small nuclear RNA using the $2^{-\Delta \mathrm{Ct}}$ method. The $\Delta \mathrm{Ct}$ values were normalized to GAPDH level. 


\section{Statistical analysis}

The statistical analyses were performed using SPSS software v. 20.0 (SPSS Inc., Chicago, USA). All the data was expressed as means \pm SD. Student's t-test or a one-way analysis of variance (ANOVA) test was performed to determine significant differences. $\mathrm{P}<0.05$ was considered statistically significant.

\section{Results}

\section{Cell morphology}

Cell morphology was observed before and after magnetic cell separation; the results are shown in Fig. 1. As can be

A

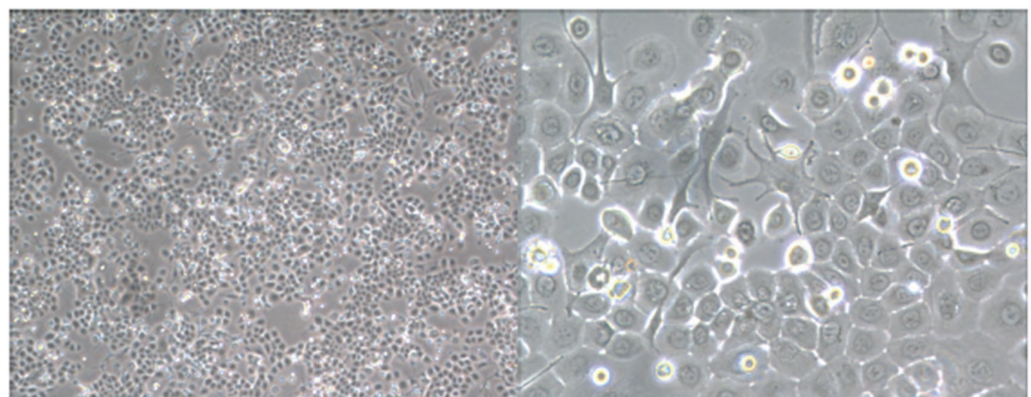

B

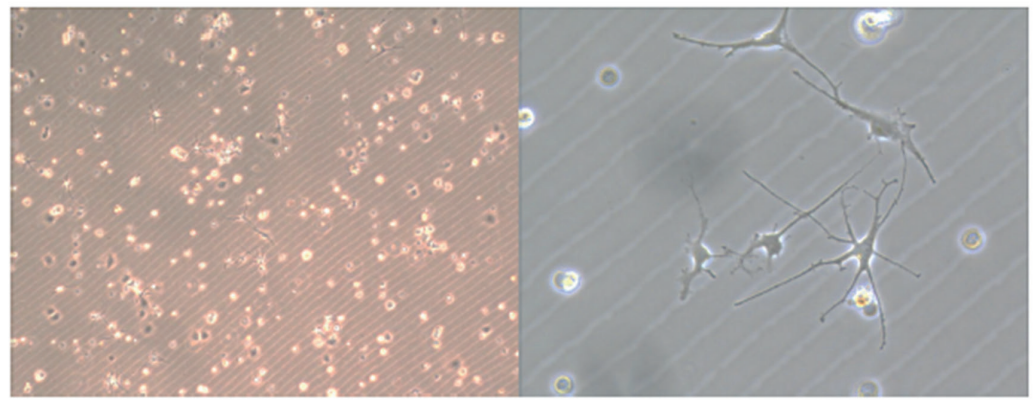

C

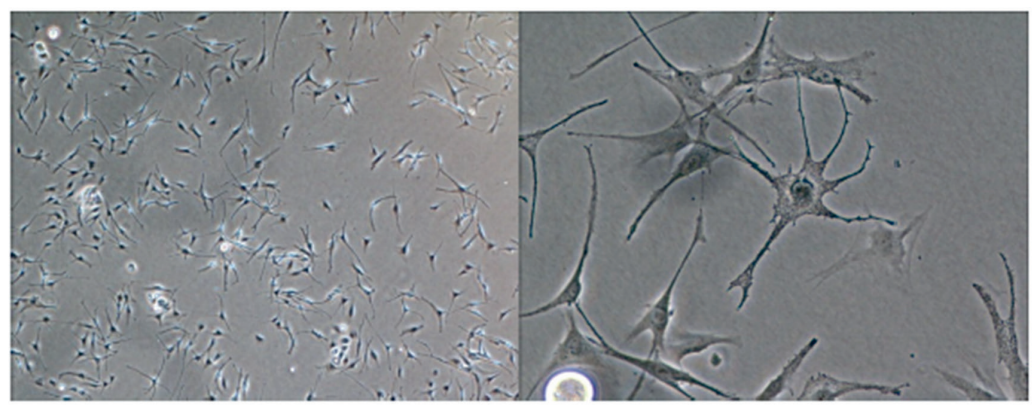

$\mathrm{D}$

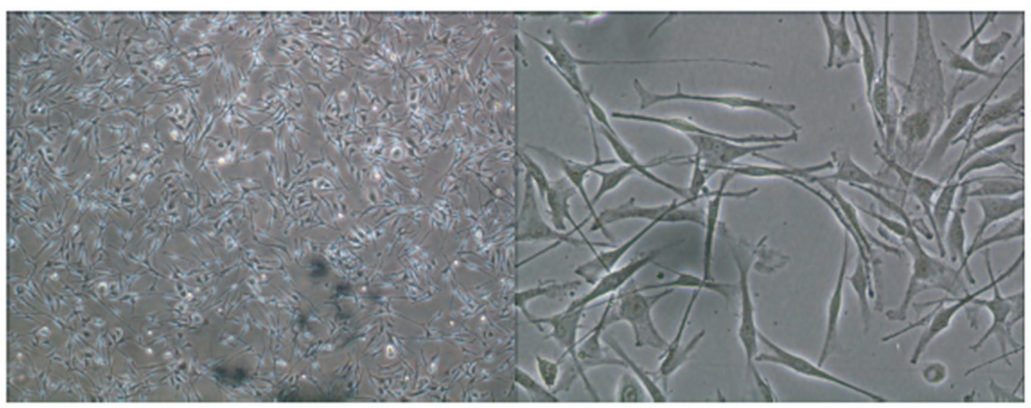

seen, after digested separated skin cells were inoculated for $24 \mathrm{~h}$, some cells sticked to the wall; the cells were round, triangular or oval; and a lot of floating cells could be seen. After 3 days, the cells gradually formed into small colonies (Fig. 1A). After magnetic bead separation, melan-A+ and PAX3+ cells comprise $10.26 \%$ of the total. After separation for $24 \mathrm{~h}$, some cells adhered to the wall, and most of them grew in bipolar or multi-stage dendrites. Most of the MC cells had 2 or 3 dendrites and no obvious KCs were observed (Fig. 1B). Before the $1^{\text {st }}$ transmission, multiple dendritic cells could be seen but they grew slowly. Melanocytes also grew slowly. However, multi-stage dendritic processes and slender axons were obvious and there were no obvious KCs. After a few generations, MCs grew fast and multi-stage dendritic growth appeared with 3 to 4 dendrites, and no obvious $\mathrm{KC}$ growth was seen (Fig. $1 C$ ). After the $2^{\text {nd }}$ transmission, the lens is covered with dendritic cells, the slender axis is prominent and no obvious $\mathrm{KC}$ growth was seen (Fig. 1D). In conclusion, the number of MCs increased as the incubation time increased, reaching a maximum on the $20^{\text {th }}$ day of culture.

\section{Absolute cell count and morphology after magnetic bead separation}

The number of mixed cells in the primary skin was approx. $2.0 \times 10^{7}$. After separation, the number of PAX3+ and melan-A+ cell was about $1.9 \times 10^{6}$. Cell passage cultivation was carried out on the $3^{\text {rd }}$ day after magnetic bead separation and the number of cells was $2.5 \times 10^{6}$ (Fig. $2 \mathrm{~A}$ ). The cells were inoculated into T75 culture flasks at the density of $1 \times 106 /$ T7 $5 \times 2$ bottles in vitro and cell morphology was observed under a microscope. As can be seen, the MC cells were lightly dyed, had a bipolar or tripolar form, and part of the extension was dendritic (Fig. 2B). Cell passage cultivation was carried out on the $10^{\text {th }}$ day after magnetic bead separation and the number of cells was $5.8 \times 10^{6}$. A large number of L-DOPAstained positive cells were observed under a microscope. The cell bodies were larger than before, the dendrites were obvious and the length varied (Fig. 2C). Cell passage cultivation was carried out on the $20^{\text {th }}$ day

Fig. 1. Cell growth situation before and after magnetic cell separation

A. Digested isolated skin cell growth after adherence to the wall of the culture flask for 3 days. Melan-A+ and PAX3+ cell growth after magnetic cell separation for (B) 1 day, (C) 10 days and (D) 20 days 
A

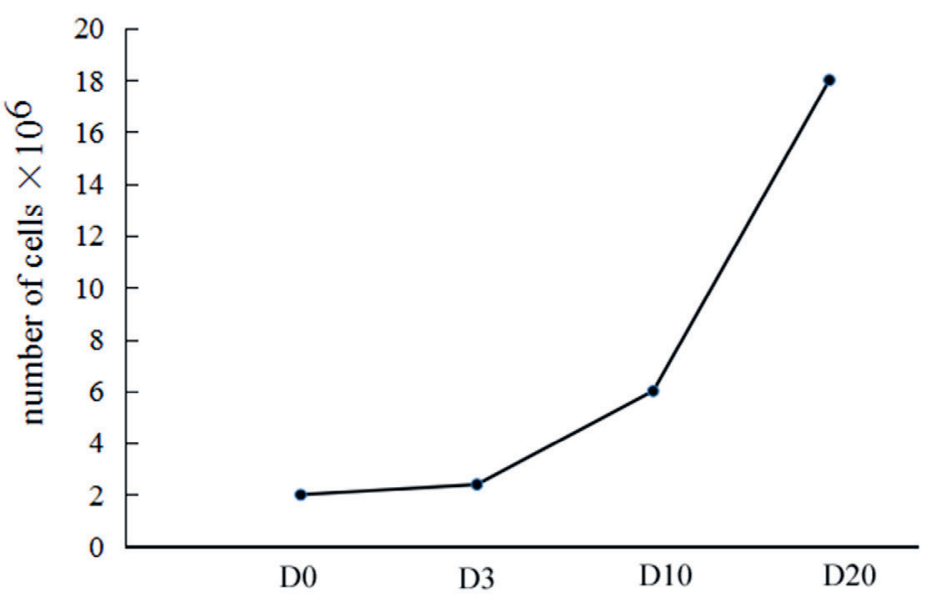

B

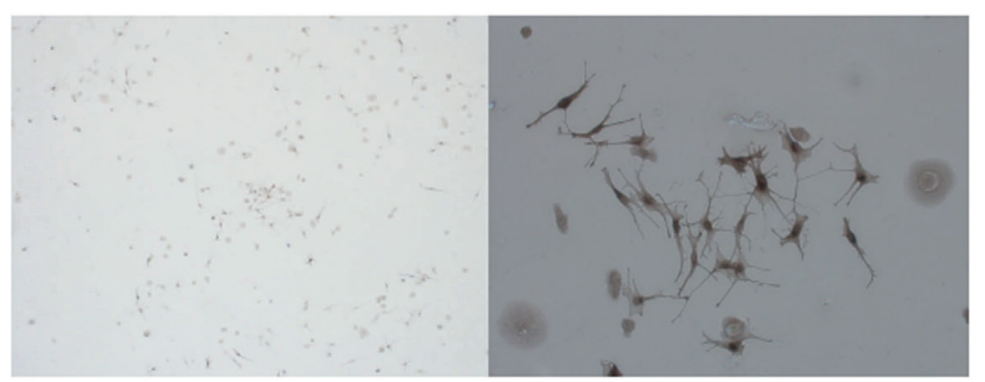

$\mathrm{C}$

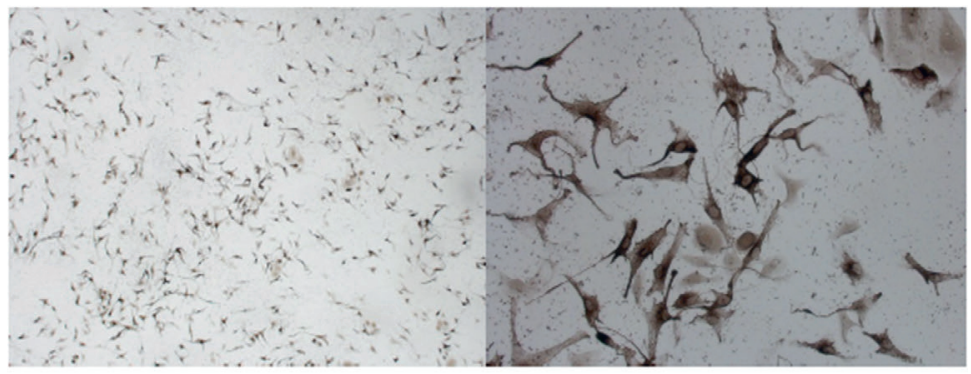

$\mathrm{D}$

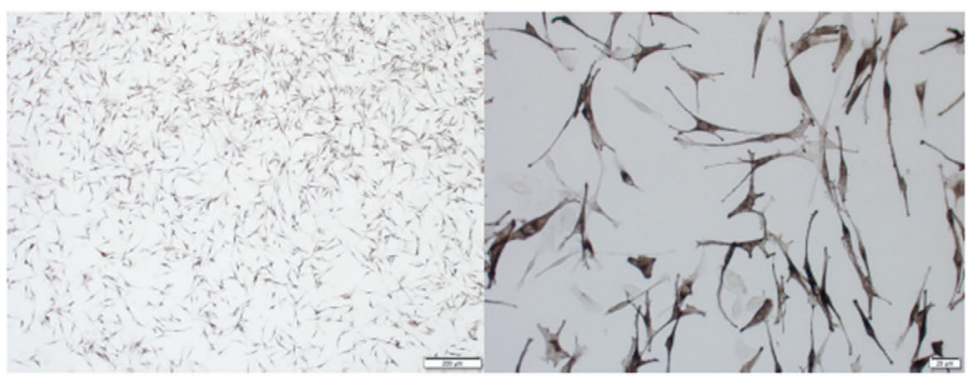

Fig. 2. The counts and morphology of melan-A+ and PAX3+ cells after magnetic cell separation

A - absolute cell counts at different times after magnetic cell separation. L-DOPA staining of melan-A+ and PAX3+ cells observed under a microscope after magnetic cell separation for (B) 1 day, (C) 10 days and (D) 20 days

separation, the optical density (OD) value was $0.316 \pm 0.002$; it was $0.469 \pm 0.012$ on the $3^{\text {rd }}$ day; $0.723 \pm 0.008$ on the $5^{\text {th }}$ day; and $1.222 \pm 0.009$ on the $7^{\text {th }}$ day. This indicated that the proliferative capacity of the cells increased with time after magnetic bead separation.

Flow cytometry was used to determine the proportion of cells in the cell cycle stages at different times, and results are shown in Fig. 3B. On day 3, the ratio of cells at the G1 stage was $71.30 \pm 0.27$; the ratio at the $S$ stage was $12.81 \pm 0.40$; and at the G2/M stage the ratio was $15.9 \pm 0.13$. On day 10 , the ratio of cells at the G1 stage was $68.19 \pm 0.80$; the ratio at the $S$ stage was $20.88 \pm 0.75$; and at the $G 2 / M$ stage it was $10.93 \pm 0.11$. On day 20 , the ratio of cells at the G1 stage was $63.83 \pm 0.20$; the ratio $S$ stage was $29.83 \pm 0.41$; and the ratio at the G2/M stage was $6.27 \pm 0.30$. Compared with the control (day 3 ), the $G 2 / M$ phase of cells was significantly decreased after magnetic bead separation, the percentage of cells at the $\mathrm{S}$ stage increased and the percentage of cells at the G1 stage decreased slightly.

\section{Changes in tyrosinase activity}

Tyrosinase activity in cells was determined at different times after magnetic cell separation, and the results are shown in Fig. 4. As shown, the OD value after separation for 3 days was $0.295 \pm 0.008$; on the $10^{\text {th }}$ day the value was $0.486 \pm 0.007$; and on the $20^{\text {th }}$ day it was $1.038 \pm 0.002$. The ratio of tyrosinase activity (D10) to tyrosinase activity (D3) was 2.0 , and the ratio of tyrosinase activity (D20) to tyrosinase activity (D3) was 4.91 . after magnetic bead separation and the number of cells was $1.83 \times 10^{7}$. Under a microscope, a large number of heavily dyed MCs were observed; the dendrites were obvious and fully extended (Fig. 2D).

\section{Changes in cell proliferation and the cell cycle}

A CCK-8 assay was used to determine the cell proliferation rate at different times; the results are shown in Fig. 3A. As can be seen, after 1 day of magnetic bead

\section{MITF, DCT and melan-A expression}

The MITF is the main regulator of melanogenesis and a key regulatory enzyme in the biosynthesis of melanin, while DCT can be regarded as a specific MSC surface antigen, but it can also be expressed in MCs. Melan-A is a major protein involved in the formation and maturation of melanosomes, and is a specific antigen on the surface of MCs. We determined the mRNA levels of MITF, DCT and melanA at different times after magnetic cell separation using reverse-transcription PCR (RT-PCR); the results are shown 

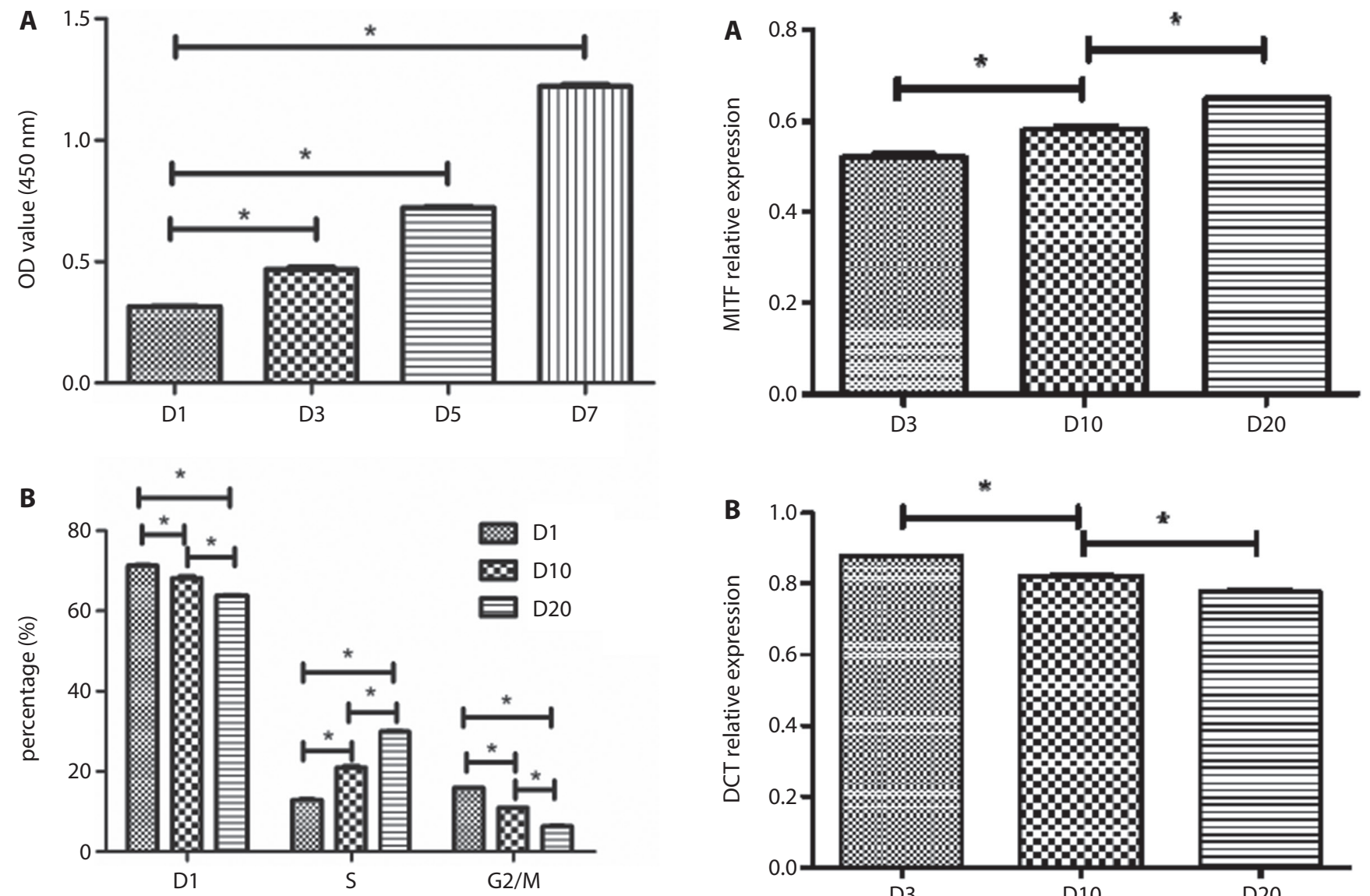

Fig. 3. Changes in melan-A+/PAX3+ cell proliferation and cell cycle after magnetic cell separation

A. Cell proliferation at different times after magnetic cell separation using CCK-8; B. Cell cycle variations at different times after magnetic cell separation using $\mathrm{FCM} ;{ }^{*} p<0.05 ;{ }^{* *} p<0.01$.

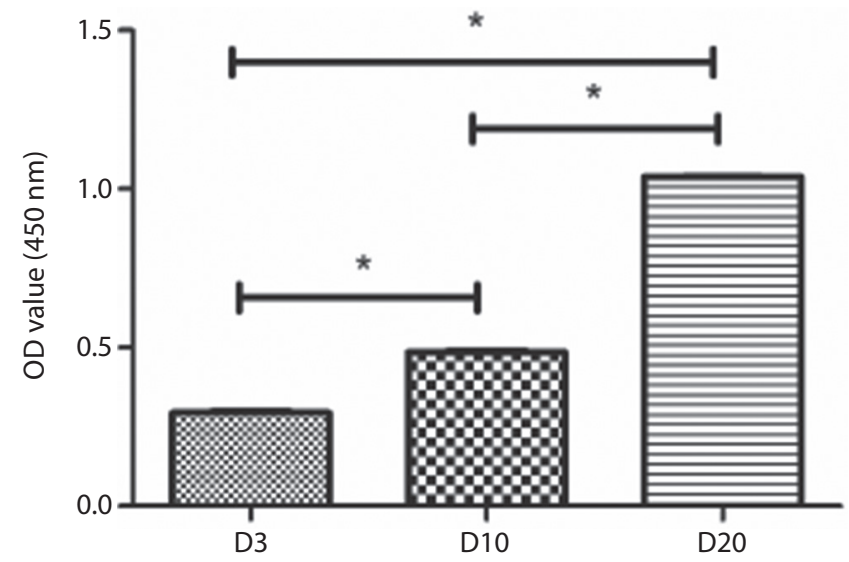

Fig. 4. Tyrosinase activity in cells at different times after magnetic cell separation by L-DOPA staining method

${ }^{*} p<0.05 ;{ }^{* *} p<0.01$.

in Fig. 5. As can be seen, the relative level of MITF and melan-A increased significantly over time, while the relative level of DCT decreased significantly $(\mathrm{p}<0.05)$. This indicated that the expression of MITF and melan-A is positively correlated with the number of days, while the expression of DCT is negatively correlated with the number of days.
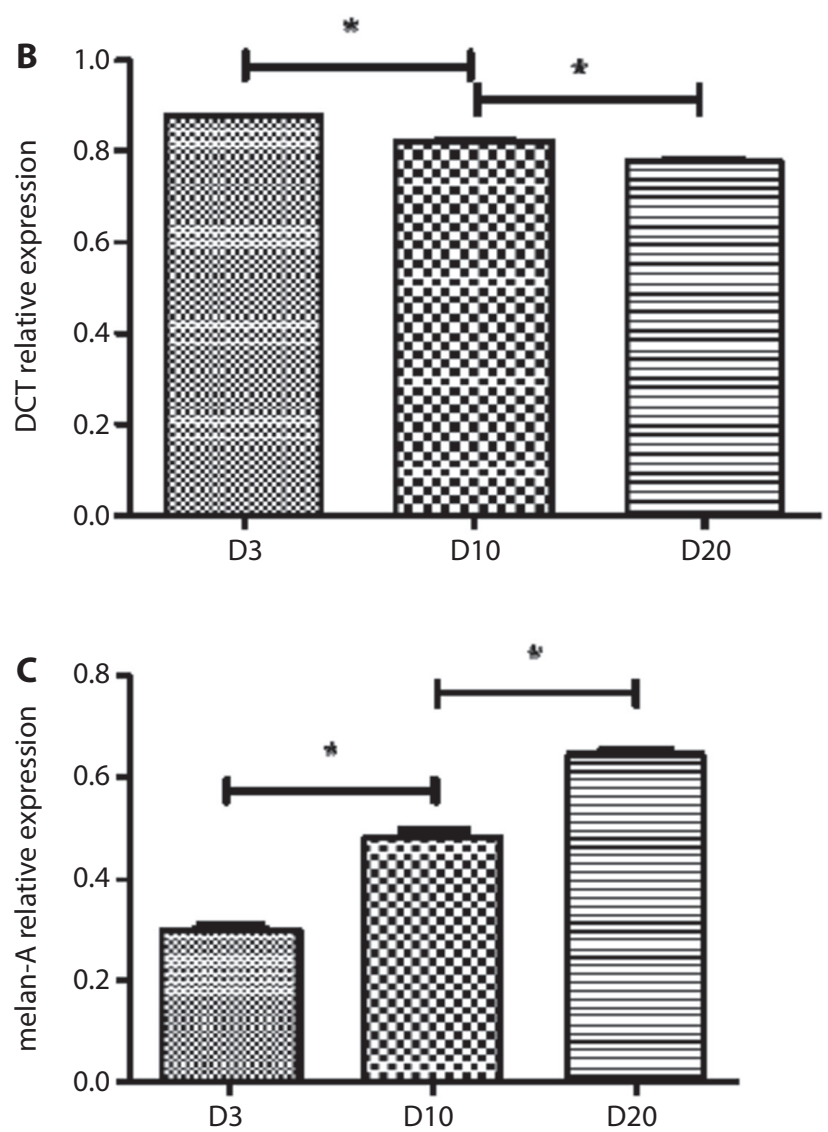

Fig. 5. The relative mRNA levels of (A) MITF, (B) DCT and (C) melan-A+ in cells cultured in vitro and magnetic cell separation for 3,10 and 20 days ${ }^{*} p<0.05 ;{ }^{* *} p<0.01$.

\section{Discussion}

At present, in vitro culture of MCs has been widely used in the experimental and clinical research of various tryptophan diseases, such as leucoderma and chloasma. Melanocytes, the main group of cells in the skin and hair coloring of vertebrates, are present in the epidermal basal layer and a small part of the hair follicle. The mammalian follicle contains a variety of cell lines and has great potential for development. Active melanin stem cells differentiate into hair follicles melanocyte (hf-mc) precursors, which 
are then generated by mature hf-mcs, whose main function is to synthesize melanin. The technique of culturing hf-mcs in vitro has opened up new research pathways and solutions for the treatment of pigmentary diseases. Melanocytes cultured in vitro can also be used to study the etiology and pathology of malignant melanoma, and to examine the efficacy and toxicity of drugs that remove pigmentation. The regulation of pigmentation involves the development, heterogeneity, regeneration, and aging of MCs and their precursors. Some studies have reported that immature MCs and MSCs could be activated to differentiate into mature MCs in leucoderma patients. ${ }^{11}$ Therefore, we believe that MSCs are involved in the differentiation and proliferation of MCs, and have therapeutic value for pigmentation disorders, trauma and melanoma.

Melanocyte surface antigens include melan-A, MITF, TYR, DCT, and others. ${ }^{12,13}$ Melan-A is one of the most important MC markers and can be expressed in melanosome and the endoplasmic reticulum of MCs. It also participates in the formation and maturation of melanosome, which as a lysosomal organelle can synthesize, store and transport melanin. Melan-A can combine with the major structural protein Pmel17 of melanosome to form a complex to participate in the transport and processing of melanosome. ${ }^{14}$ Melan-A can be expressed in mature MCs, but not on the surface of MSCs. Therefore, in this study, melan-A was selected as a marker antigen of mature MCs for $\mathrm{MC}$ screening in mixed cells. The MITF is a key transcription factor that encodes $\mathrm{MC}$ development. It plays an important role in the various processes of $\mathrm{MC}$ development, including neural crest differentiation, melanoblast growth and terminal MC differentiation. ${ }^{15}$ The DCT, also named TRP-2, is a mouse gene. The carboxyl terminal and membrane domain of DCT play a key role in the formation of melanosome. The DCT can form into a tyrosinase complex with TYR and TRP-1. DCT and TRP-1 mutations can induce pigment changes rather than depigmentation. Therefore, DCT and TRP-1 play a modifying role in melanogenesis. The DCT can be expressed not only in embryonic MCs, but also in mature MCs. The surface of MSCs lacks MC surfacerelated antigens such as TYR, MITF, melan-a, SOX10, KIT, and others, and only expresses PAX3 and DCT. ${ }^{16,17}$ PAX3 is an important transcription factor in the neuroectoderm of embryo development and is first expressed in anterior neural crest cells during the embryonic period. ${ }^{18}$ The pairing domain and homologous domain of PAX3 can promote the binding of PAX3 to DNA by recognizing the common sequences of DNA, which activates the transcription of target genes. ${ }^{19}$ In the embryonic stage, PAX3 can inhibit cell apoptosis by targeting p53 to make sure the cells are fully developed. ${ }^{20}$ It can promote the migration of MCs from neural crest cells and promote the migration of MSCs from hair follicles to dermal papillae. ${ }^{21}$ Therefore, in this study, PAX3 was used as a marker to analyze and detect MSCs.

In this study, melan-A + and PAX3+ MSCs were isolated from mixed cells digested from skin and cultured in vitro to establish MC and MSC in vitro culture models. The key to culturing MCs is the selection of culture conditions and preparation of the culture medium, since the growth of MCs is negligible under standard cell culture conditions. In this experiment, we used a medium containing HMGS-2 and endothelin (ET), without 12-O-tetradecanoylphorbol13-acetate (TPA) or cholera toxin (CT). HMGS-2 can reduce the possibility of cell mutagenesis, and is usually used to culture neonatal MCs or MSCs, ${ }^{22}$ increasing the availability of cultured cells for clinical use. At different stages of the culture process, we observed that dendrites of separated MCs constantly increased over time and no obvious KCs or other cell growth was observed. This means that magnetic cell separation can separate MCs from other cells in mixed skin cells and maintain MC characteristics during the culture process. However, during the culture stage, we found that some cells with large amounts of cytoplasm had no obvious dendrites. To verify whether these cells are PAX3+ MSC cells and whether they participate in the differentiation and maturation of MCs, we performed L-DOPA staining on the cells at different stages of the culture, counted the L-DOPA-positive cells and calculated their proportion in the cultured cells. The L-DOPA staining is a classic method for identifying active MCs and positive staining indicates the existence of active tyrosinase in melanosomes. ${ }^{23}$ Both MSCs and differentiated MCs lack functional tyrosinase and cannot produce melanin; only mature MCs produce melanin. ${ }^{24}$ Therefore, as primitive cells unable to synthesize melanin particles, L-DOPA staining of MSCs should be negative, while the L-DOPA staining of MCs with active tyrosinase is positive. Our results showed that the number of positive L-DOPA stained PAX3+ and melan-A+ cells increased, and most cells gradually differentiated into mature MCs. This provides a cellular biological model for further study of the process and mechanism of human MC differentiation and maturation.

In order to further study cell growth after magnetic cell separation, a proliferation curve was plotted using CCK-8 and the cell cycle was studied with FCM. The results of CCK-8 showed that the number of cells increased as the duration of the culture increased. The results of FCM showed that after magnetic cell separation, the cells in G1 phase decreased with the extension of the culture time, indicating that cells in the static phase decreased and MSCs develop into mature MCs. Cells in S phase increased and cells in the G2/M phase decreased, which indicates that the DNA replication period is prolonged and $\mathrm{MC}$ proliferation is active. Therefore, we inferred that cell proliferation capacity increased; the cells in the stationary phase gradually reduced; and cells in the inactive phase gradually increased after in vitro culturing and magnetic cell separation.

In order to study the biological function of cells after separation, we examined the tyrosinase activity and gene expression of the cells. Tyrosinase, as a key enzyme in melanin metabolism, mainly exists in mature MCs and cannot be detected in MSCs. ${ }^{25}$ Our study showed that tyrosinase 
activity increased with the duration of the culture, which indicated that the ability to secrete melanin was significantly improved and the content of melanin in MCs increased. Both MSCs and differentiated MCs lack functional tyrosinase and could not produce melanin; only mature MCs can produce melanin. The MITF is the main regulator of melanogenesis and the key regulator of melanin biosynthesis. The $D C T$ can be used as a specific surface antigen of MSCs and can also be expressed in MCs. Melan-A is a major protein involved in the formation and maturation of melanosomes, and a specific surface antigen of MCs. Therefore, we mainly studied the relative mRNA levels of MITF, DCT and melan-A in cells cultured in vitro after magnetic cell separation. Our study showed that the relative expression levels of MITF and melan-A in cells increased with culture time, while the relative mRNA levels of DCT decreased over time. Therefore, we believe that after magnetic bead separation, the cells have the characteristics of MSCs and MCs, and that MSCs constantly differentiate into mature MCs.

\section{ORCID iDs}

Weimin Shi (1) https://orcid.org/0000-0003-2305-3503 Xingyu Mei (1) https://orcid.org/0000-0003-1515-6916 Jie Huang (i) https://orcid.org/0000-0002-2981-2403 Yue Sun (D) https://orcid.org/0000-0002-6638-5850 Zhouwei Wu (D) https://orcid.org/0000-0002-7247-1560

\section{References}

1. Basha, K, Anjaneyulu E, Gopi Krishna S, Niaz Parveen DD, Gudivada S. Plants used in the treatment of leucoderma by the tribals of Yerramalai Forest of Kurnool District, Andhra Pradesh, India. Journal of Ethnobiology and Traditional Medicine. 2014;121:761-766.

2. Szczurko O, Boon HS. A systematic review of natural health product treatment for vitiligo. BMC Dermatol. 2008;8:2.

3. Usha SS, Narain A. Traditional treatment of leucoderma by Kol tribes of Vindhyan region of Uttar Pradesh. Indian Journal of Traditional Knowledge. 2010;9(1):173-174.

4. Ali SA, Naaz I. Biochemical aspects of mammalian melanocytes and the emerging role of melanocyte stem cells in dermatological therapies. Int J Health Sci (Qassim). 2018;12(1):69-76.

5. Imokawa G, Autocrine and paracrine regulation of melanocytes in human skin and in pigmentary disorders. Pigment Cell Res. 2004; 17(2):96-110.

6. Moussa R. Immunohistochemical expression of melan-A in canine melanic tumors. Bulletin of the University of Agricultural Sciences \& Veterinary Medicine Cluj-Napoca. 2011;68(1):260-267.

7. Sandu C, Dumas M, Malan A, et al. Human skin keratinocytes, melanocytes, and fibroblasts contain distinct circadian clock machineries. Cell Mol Life Sci. 2012;69(19):3329-3339.
8. Birlea SA, Costin GE, Roop DR, Norris DA. Trends in Regenerative Medicine: Repigmentation in Vitiligo Through Melanocyte Stem Cell Mobilization. Med Res Rev. 2017;37(4):907-935. doi:10.1002/med. 21426

9. Hoerter JD, Bradley P, Casillas A, et al. Extrafollicular dermal melanocyte stem cells and melanoma. Stem Cells Int. 2012;2012:407079.

10. Sextius $P$, Betts R, Benkhalifa I, et al. Polygonum multiflorum Radix extract protects human foreskin melanocytes from oxidative stress in vitro and potentiates hair follicle pigmentation ex vivo. Int $\mathrm{J}$ Cosmet Sci. 2017;39(4):419-425.

11. Nishimura EK. Melanocyte stem cells: A melanocyte reservoir in hair follicles for hair and skin pigmentation. Pigment Cell Melanoma Res. 2011;24(3):401-410.

12. Zhang P, Liu W, Yuan X, Li D, Gu W, Gao T. Endothelin-1 enhances the melanogenesis via MITF-GPNMB pathway. BMB Rep. 2013;46(7): 364-369.

13. Hwang JA, Park NH, Na YN, et al. Coumestrol downregulates melanin production in melan-a murine melanocytes through degradation of tyrosinase. Biol Pharm Bull. 2017;40(4):535-539.

14. Hoashi T, Tamaki K, Hearing VJ. The secreted form of a melanocyte membrane-bound glycoprotein (Pmel17/gp100) is released by ectodomain shedding. FASEB J. 2010;24(3):916-930.

15. Seberg HE, Van OE, Cornell RA. Beyond MITF: Multiple transcription factors directly regulate the cellular phenotype in melanocytes and melanoma. Pigment Cell Melanoma Res. 2017;30(5):454-466.

16. Garbuzov A, Pech MF, Hasegawa K, et al. Purification of GFRa1+ and GFRa1-spermatogonial stem cells reveals a niche-dependent mechanism for fate determination. Stem Cell Rep. 2018;10(2):553-567.

17. Negro S, Imsland F, Valera M, Molina A, Solé M, Andersson L. Association analysis of KIT, MITF, and PAX3 variants with white markings in Spanish horses. Anim Genet. 2017;48(3):349-352.

18. Xiao J, Li Q, Qu P, et al. Isolation of bovine skin-derived precursor cells and their developmental potential after nuclear transfer. Cellular Reprogram. 2016;18(6):411-418.

19. Moore S, Ribes V, Terriente V, Wilkinson D, Relaix F, Briscoe J. Distinct regulatory mechanisms act to establish and maintain Pax3 expression in the developing neural tube. PLoS Genet. 2013;9(10):e1003811.

20. Wang L, Lin S, Yi D, et al. Apoptosis, expression of PAX 3 and P53, and caspase signal in fetuses with neural tube defects. Birth Defects Res. 2017;109(19):1596-1604.

21. Choi $\mathrm{H}$, Jin $\mathrm{SH}$, Han $\mathrm{MH}$, et al. Human melanocytes form a PAX3expressing melanocyte cluster on Matrigel by the cell migration process. J Dermatol Sci. 2014;76(1):60-66.

22. Hirobe T. Endothelins are involved in regulating the proliferation and differentiation of mouse epidermal melanocytes in serum-free primary culture. J Investig Dermatol Symp Proc. 2001;6(1):25-31.

23. Muñoz-Muñoz JL, Acosta-Motosa JR, Garcia-Molina F, et al. Tyrosinase inactivation in its action on dopa. Biochim Biophys Acta Proteins Proteom. 2010;1804(7):1467-1475.

24. Tang J, Cheng B, Jing L. Primary culture of human face skin melanocytes for the study of hyperpigmentation. Cytotechnology. 2014;66(6): 891-898.

25. Şohretoglu D, Sari S, Barut B, Ozel A. Tyrosinase inhibition by some flavonoids: Inhibitory activity, mechanism by in vitro and in silico studies. Bioorg Chem. 2018;15(81):168-174. 